\title{
Practice, Training Need of Disaster Preparedness and Associated Factors in Nursing Staffs Working at Emergency Department, Amahra Regional State Referral Hospitals, Ethiopia, 2020G.C. A Hospital Based Cross Sectional Study
}

Lehulu Tilahun ( $\square$ lehulut333@gmail.com )

Wollo University, Department of Emergency and Ophthalmic Nursing, Dessie, Ethiopia

Birhanu Dessu

Wollo University

Mulusew Zeleke

Wollo University

Research article

Keywords: Practice, training need, Disaster preparedness

Posted Date: September 10th, 2020

DOI: https://doi.org/10.21203/rs.3.rs-62830/v1

License: (1) (i) This work is licensed under a Creative Commons Attribution 4.0 International License.

Read Full License 


\section{Abstract}

Background: Globally disasters are increasing at alarming rate that leads giving training and making preparing frontline emergency department nurses an important issue. Although disasters are manageable and preventable they are still considered as a major public health issues.

Methods: Hospital based cross sectional study used to come up with the findings. All emergency department working nurses from the region referral hospitals were assumed as study subjects. The disaster information on respondents was gathered with self-administered written questionnaires. Data entry and coding was made by using epidata software manager v4.6.0.2 and further exported to spss version 26 for further analysis.

Result: In our study finding most participants were males 68(66.7\%). In addition mean age of data respondents were $31.2 \pm 5.8$. It is found that $25(24.5 \%)$ of participants have adequate practice on the contrary $75(75.5 \%)$ of respondents have inadequate practice. Also, $40(39.2 \%)$ respondents need training on first aid and treatment principles, $37(36.3 \%)$ need training on disaster preparedness and $31(30.4 \%)$ need training on basic principles of disaster response. In multivariate analysis variables with practice of disaster preparedness are training performed in a hospital set up $\{\mathrm{P}$ value $=0.047, \mathrm{OR}: 0.282,95 \% \mathrm{Cl}$ : $(0.081-0.985)\}$ and simulation done in hospital $\{\mathrm{P}$ value $=0.002, \mathrm{OR}: 0.071,95 \% \mathrm{Cl}:(0.055-0.530)\}$ were significantly associated.

Conclusions: Skill level of emergency department nurses with regard to disaster preparedness is inadequate so that training supported with drills \& simulation and education are mandatory.

\section{Background}

We can define disaster as an emergency situation that may endanger the life of the population (1-3). Worldwide, disaster can occur every day that intern affect the community at large(2). World health organization/WHO gives a big consideration for this area and supports and advises states to build up their own disaster preparedness strategies(3). This emergency event my end up with disruption of properties in addition with human life. So that, the role of emergency department/ED nurses comes here which intern initiates the need of capacity building for these health professionals(4).

Globally disasters are increasing at alarming rate that leads giving training and making preparing frontline emergency department nurses an important issue $(2,5)$. Especially this disruptive event puts a visible damage for less developed countries mainly due their economy to coup up with disaster impacts(2). Worldwide about 1.6 million people died because of disaster impacts. For underdeveloped states the impact becomes a double burden in addition to infectious diseases(6). Although disasters are manageable and preventable they are still considered as a major public health issues. In Ethiopia, currently traumatic injuries especially road traffic accidents are major issues(7).

\section{Objectives}


QTo describe practice of disaster preparedness among nurses working at emergency department, referral hospitals

$\nabla$ To identify the training need of disaster preparedness of nurses working at emergency department, referral hospitals

$\nabla$ To explore associated factors of disaster preparedness of nurses working at emergency department, referral hospitals

\section{Methods}

A hospital based cross-sectional study design was conducted at emergency department of Amahara regional state referral hospitals in March to April 2020G.C. All emergency department working nurses during the study period at Amhara regional state referral hospitals were assumed as study subjects.

All emergency department working nurses at Amhara regional state referral hospitals were eligible for the study. On the contrary those in study, annual and maternity leave were not eligible for this study.

All emergency department working nurses from the region referral hospitals were assumed as study subjects. The disaster information on respondents was gathered with self-administered written questionnaires. Five data collectors and two supervisors in a position to collect needed data from March to April, 2020G.C.

Data was collected from knowledge, attitude and practice questionnaire and emergency preparedness information questionnaire/EPIQ taken from (2) with some modification and that was applicable with many papers.

To keep the quality of the study, we conducted training for both data collectors and supervisors. In addition a tool of emergency preparedness information questionnaire was used. The Wiscon nurses association recommended to use the tool(2). Similarly, pretest was done on $5 \%$ of respondents at Boru meda hospital before the real data collection process commences. Filled questioners were reviewed by supervisor principal investigator before data entry initiates.

Data entry and coding was made by using epidata software manager v4.6.0.2 and further exported to spss version 26 for further analysis. Then findings was presented by the help of tables and charts. The association of independent variables with that of dependent variables was assessed by using logistic regression.

We went forward only when got an ethical clearance from the research an ethical review office of Wollo University. After that permission was received from the respective hospital managements. Finally, an oral consent obtained from participants and the objective of the study cleared up to them and participation was only on volunteer bases. 


\section{Results}

From the study a total of 115 emergency department working nurses were seen. Among them 106 were eligible for the study, from it 102 subjects were already participated in the study and data was collected with a response rate of $96.2 \%$ due to not returning certain tools.

In our study finding most participants were males 68(66.7\%). In addition mean age of data respondents were 31.2 \pm 5.8 . Most participants' marital status was married $60(58.8 \%)$ and single $41(41.2 \%)$. Most data respondents $39(38.2 \%)$ have a working duration of 3-6years. Majority $82(80.4 \%)$ participants have a BSC in comprehensive nursing (Table 1).

\section{Table 1. Socio demographics on disaster preparedness, Emergency Department, Amhara Regional State Referral Hospitals, Ethiopia,}

\begin{tabular}{|llll|}
\hline Variables & & Frequency & Percent (\%) \\
\hline & Male & 68 & 66.7 \\
\hline Marital Status & Female & 34 & 33.3 \\
\hline & Single & 41 & 40.2 \\
\hline Married & 60 & 58.8 \\
\hline Clinical Experience & Divorced & 1 & 1.0 \\
\hline & $<3$ years & 14 & 13.7 \\
& $3-6$ years & 39 & 38.2 \\
\hline 6-9 years & 17 & 16.7 \\
\hline Highest level of education attained & BSC incomprehensive Nurse & 82 & 31.4 \\
& BSC in ECCN & 9 & 80.4 \\
\hline & MSC in EMCCN & 3 & 2.9 \\
\hline & Others* & 8 & 7.8 \\
\hline
\end{tabular}

*MPH in epidemiology, EMT (Emergency Medical Technician)

The paper depicted that among all data responders majority respondents $56(54.9 \%)$ responded as disaster drills not done in their hospital setup. Only 19(18.6\%) of participants informed as disaster drill performed in their hospital. In addition 27(26.5\%) participants do not know whether disaster drills done in their hospital or not. 
Similarly, most participants $80(78.4 \%)$ responded as there is no ongoing disaster training performed in their hospital but only $15(14.7 \%)$ participants responded as there is ongoing disaster training done in their hospital. 7(6.9\%) do not know whether or not disaster training was done.

As well 67(65.7\%) tells us the disaster plan is not periodically updated but 19(18.6\%) responded as their hospital disaster plan periodically updated. Also 16(15.7\%) don not have information to the issue. Among respondents responded as "yes", 12(63.16\%) said as disaster plan updated when need arises. Others $4(21.05 \%), 1(5.26 \%), 2(10.53 \%)$ said as disaster plan revised in every 3-6months, every 6 months and every year respectively. Mean of disaster practice of participants found as $5.97 \pm 1.21$. So that it is found that $25(24.5 \%)$ of participants have adequate practice on the contrary $75(75.5 \%)$ of respondents have inadequate practice (Table 2 \& Fig. 1).

\section{Table 2. Practice of data respondents with regard to disaster preparedness, Emergency Department, Amhara Regional State Referral Hospitals, Ethiopia,}




\begin{tabular}{|c|c|c|c|}
\hline Variables & Frequency & & $\begin{array}{l}\text { Percent } \\
(\%)\end{array}$ \\
\hline \multirow[t]{4}{*}{ Are Disaster drills done at your Hospital? } & Yes & 19 & 18.6 \\
\hline & No & 56 & 54.9 \\
\hline & Don't know & 27 & 26.5 \\
\hline & Total & 102 & 100.0 \\
\hline \multirow[t]{4}{*}{ Is there ongoing Disaster Training? } & Yes & 15 & 14.7 \\
\hline & No & 80 & 78.4 \\
\hline & Don't know & 7 & 6.9 \\
\hline & Total & 102 & 100.0 \\
\hline \multirow{4}{*}{$\begin{array}{l}\text { Does the Emergency Operational (disaster) plan } \\
\text { periodically Updated? }\end{array}$} & Yes & 19 & 18.6 \\
\hline & No & 67 & 65.7 \\
\hline & Don't know & 16 & 15.7 \\
\hline & Total & 102 & 100.0 \\
\hline \multirow[t]{5}{*}{ If Yes how Often? } & $\begin{array}{l}\text { When need } \\
\text { arises }\end{array}$ & 12 & 63.16 \\
\hline & $\begin{array}{l}\text { Every 3-6 } \\
\text { months }\end{array}$ & 4 & 21.05 \\
\hline & $\begin{array}{l}\text { Every } 6 \\
\text { months }\end{array}$ & 1 & 5.26 \\
\hline & Every Year & 2 & 10.53 \\
\hline & Total & 17 & 100.00 \\
\hline Mean $\pm S D=5.97 \pm 1.21$ & & & \\
\hline
\end{tabular}

Among all respondents 31 (30.4\%) need training on basic principles of disaster response. Also 40(39.2\%) need on first aid and treatment principles. 21(20.6\%), 27(26.5\%), 37(36.3\%) and 18(17.6\%) of participants need training on rescue and transport of wounded, triaging, disaster preparedness and response, post disaster psychological relief, and epidemic prevention respectively.

The training need of respondents on disaster preparedness resulted with mean of 12.059 \pm 2.14 (Table 3).

\section{Table 3. Training need of respondents $(n=102)$ on disaster preparedness at Emergency Department, in Amhara Regional State Referral Hospitals, Ethiopia.}




\begin{tabular}{|llll|}
\hline Variables & & Frequency & Percent (\%) \\
\hline Basic principles of disaster response & Yes & 31 & 30.4 \\
\hline First aid and Treatment principles & No & 71 & 69.6 \\
\hline Rescue and transport of the wounded & 40 & 39.2 \\
\hline No & 62 & 60.8 \\
\hline Yn Triaging & No & 81 & 20.6 \\
\hline Disaster preparedness and response plans & Yes & 37 & 79.4 \\
\hline Nes & 27 & 26.5 \\
\hline Nost disaster psychological relief & No & 75 & 73.5 \\
\hline & Yes & 18 & 17.6 \\
\hline Mean \pm SD = 12.059 \pm 2.14 & No & 84 & 82.4 \\
\hline
\end{tabular}

By using a bivariate analysis, variables that were significantly associated with that of practice of disaster preparedness are having awareness on disaster, training performed in a hospital and simulation done at hospital setup. For that, Practice in disaster preparedness is 3 times more likely associated with having disaster awareness than those not having awareness with an odds ratio of $\{P$ value $=0.223$, OR: 3.354, $95 \% \mathrm{Cl}$ : (1.073-10.481)\}. Also, training not performed in a hospital is $85 \%$ less likely linked with practice of disaster preparedness with an odds ratio of $\{\mathrm{P}$ value $=0.001, \mathrm{OR}: 0.150,95 \% \mathrm{Cl}$ : $(0.047-0.482)\}$. Similarly, simulation not being done at a hospital setup is $87 \%$ less likely associated with practice of disaster preparedness with an odd of $\{\mathrm{P}$ value $=0.000, \mathrm{OR}: 0.127,95 \% \mathrm{Cl}$ : $(0.043-0.378)$.

By using Multivariate analysis variables that are significantly associated with practice of disaster preparedness are Training performed in a hospital set up and simulation done in hospital. Thus, Not performing training in a hospital is $72 \%$ less likely affected practice in disaster preparedness with an odd ratio of $\{\mathrm{P}$ value $=0.047, \mathrm{OR}: 0.282,95 \% \mathrm{Cl}$ : (0.081-0.985) $\}$. In addition, practice of disaster preparedness is $92 \%$ less likely associated with no simulation at hospital with an odds of $\{P$ value $=0.002,0 R: 0.071$, $95 \% \mathrm{Cl}:(0.055-0.530)\}$

\section{Table 4. Result of risk estimate on disaster and emergency handling preparedness at Emergency Department, in Amhara Regional State Referral Hospitals, Ethiopia, 2020.}


Odds Ratio

Practice of disaster

preparedness

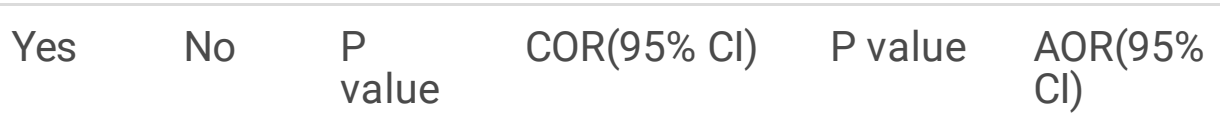

Training Performed Yes

in a hospital

$\begin{array}{lllllll} & 9 & 6 & & & \\ \text { No } & 16 & 71 & 0.001 * & \begin{array}{l}0.150(0.047- \\ 0.482)\end{array} & 0.047 * * & 0.282(0.081- \\ & & & & & 0.985)\end{array}$

Simulation done at Yes $20 \quad 26$

hospital set up

\begin{tabular}{|ccccclll|} 
& No & 5 & 51 & $0.000 *$ & $\begin{array}{l}0.127(0.043- \\
0.378)\end{array}$ & $0.002 * *$ & $\begin{array}{l}0.071(0.055- \\
0.530)\end{array}$ \\
$\begin{array}{lccccll}\text { Having disaster } \\
\text { awareness }\end{array}$ & Yes & 7 & 8 & $0.037 *$ & $\begin{array}{l}3.354(1.073- \\
10.481)\end{array}$ & 0.223 & $\begin{array}{l}0.370(0.075- \\
1.832)\end{array}$ \\
& No & 18 & 69 & & & & \\
\hline
\end{tabular}

COR $=$ Crude Odds ratio, AOR= Adjusted Odds Ratio, C.I= Confidence Interval

* Variables significantly associated in bivariate analysis

**variables significantly associated in through multivariate analysis

\section{Discussion}

This reach finding shows $75.5 \%$ participants has inadequate practice in terms of disaster preparedness. On the contrary only $24.5 \%$ respondents has adequate practice towards disaster preparedness at hospital emergency department level. This finding is supported with study done at Malaysia and Tehran found that only those who participated on disaster handling, education and training have adequate practice. Also in Saudi Arabia there is lack of skill (8-10).

The study finding showed as $56(54.9 \%)$ responded as disaster drills not done in their hospital setup. On the other hand, $80(78.4 \%)$ responded as there is no ongoing disaster training performed in their hospital. In similar manner it is supported from research done at Johannesburg hospital, most $92.8 \%$ nurses showed as they need training on disaster readiness handling. Also in the same way in Johannesburg of other hospital nurses responded as $100 \%$ of disaster skill is needed $(9,11)$. 
We have found that $40(39.2 \%)$ respondents need training on first aid and treatment principles, 37(36.3\%) need training on disaster preparedness and 31(30.4\%) need training on basic principles of disaster response.

The paper reveals that through bivariate analysis, variables that were significantly associated with that of practice of disaster preparedness are having awareness on disaster, training performed in a hospital and simulation done at hospital setup. Further analysis through Multivariate analysis, variables that are significantly associated with practice of disaster preparedness are Training performed in a hospital set up and simulation done in hospital. This is supported with findings at Tehran, disaster education and training increases skill level of professionals(5).

\section{Conclusions}

To conclude, we have got as $75.5 \%$ participants has inadequate practice in terms of disaster preparedness. But, only $24.5 \%$ respondents has adequate practice towards disaster preparedness at hospital emergency department level.

We can conclude also as disaster drills not done in hospital setup in $54.9 \%$. We can say disaster drill not performed in hospital (only $18.6 \%$ ) respondents received drills). As well, $80(78.4 \%$ ) responded as there is no ongoing disaster training performed in their hospital. Only $14.7 \%$ participants responded as there is ongoing disaster training. As well $65.7 \%$ participants tells us the disaster plan is not periodically updated.

Also this paper revealed that, $39.2 \%$ need training on first aid and treatment principles and $36.3 \%$ need training on disaster preparedness and $30.4 \%$ need training on basic principles of disaster response at referral hospital emergency departments.

Finally, in bivariate analysis, variables that were significantly associated with that of practice of disaster preparedness are having awareness on disaster, training performed in a hospital and simulation done at hospital setup. Further analysis through Multivariate analysis, variables that are significantly associated with practice of disaster preparedness are Training performed in a hospital set up and simulation done in hospital.

\section{RECOMMENDATION}

The finding resulted most respondents as having an inadequate skill with regard to disaster preparedness, the regional health office to facilitate a skill based training through dills or simulation to health professional nurses working at emergency and accident departments with regard to disaster preparedness.

As per the finding of this research, even though the attitude level of respondents towards accident and disaster handling preparedness is better, respondents' knowledge and familiarity level towards disaster is below expected. So, we recommend the regional health bureau of Amhara Region better if it gives 
attention on staff capacity building especially for those nurses working at emergency department that mainly helps to coup up with increasing disasters.

In addition the respective regional referral hospital is better to strengthen short term trainings and long term education for front line department working professionals on disaster preparedness in collaboration with health office and other concerned sectors. In similar manner emergency department working nurses are expected to share their part through further reading and in turn enhancing their skill of disaster preparedness.

\section{Abbreviations}

ED: Emergency Department

EPIQ: Preparedness Information Questionnaire

WHO: World Health Organization

\section{Declarations}

\section{Ethics approval and consent to participate}

We went forward only when got an ethical clearance from the research an ethical review office of Wollo University. After that permission was received from the respective hospital managements. Finally, a written consent obtained from participants and the objective of the study cleared up to them and participation was only on volunteer bases. . Confidentiality of the information is kept by not mentioning respondents' name. For the written consent the ethical review office of Wollo University already approved and directed for future tasks.

\section{Consent for Publication}

Not applicable

\section{Availability for data and materials}

The data set used for analysis already found on the hands of the corresponding author on reasonable request.

\section{Competing interests}

Author declared as there is no conflict of interest.

\section{Funding}


The role of the budget provider for this study was it initiates for the development of an area of interest, then facilitates the proposal defense and evaluation and finally approves and fully covered the fund.

\section{Authors Contribution}

Author contributed from conception the research design to data collection, analysis, interpretation and total research write up also approval for publication and agreed to be accountable for all aspects of the work. That is $L T$, brought the original idea. $L T, B D \& M Z$ drafted and revised the work. $L T, B D$ and $M Z$ supervised data collection. $L T, B D$ and $M Z$ analyzed and interpreted the finding. $M Z, L T, B D$ wrote the manuscript. Also all agreed for publication

\section{ACKNOWLEDGEMENTS}

We want to say thanks to Wollo University for being budget provider and creating an opportunity to run this research paper.

\section{References}

1. Khorram-Manesh A. Handbook of Disaster and Emergency Management. Gothenburg, İsveç: Kompendiet Kasım. 2017;15:2018.

2. Ibrahim FAA. Nurses knowledge, attitudes, practices and familiarity regarding disaster and emergency preparedness-Saudi Arabia. American Journal of Nursing Science. 2014;3(2):18-25.

3. Organization WH. Disaster preparedness and response: World Health Organization regional office for Europe. 2009.

4. Ismail A, Saiboon IM, editors. Disaster management: a study on knowledge, attitude and practice of emergency nurse and community health nurse. BMC public health; 2012: Springer.

5. Pourvakhshoori S, Khankeh HR, Mohammadi F. Emergency and Disaster Preparedness in Nurses: A Concept Analysis. Journal of Holistic Nursing And Midwifery. 2017;27(1):35-43.

6. Paganini M, Borrelli F, Cattani J, Ragazzoni L, Djalali A, Carenzo L, et al. Assessment of disaster preparedness among emergency departments in Italian hospitals: a cautious warning for disaster risk reduction and management capacity. Scandinavian journal of trauma, resuscitation and emergency medicine. 2016;24(1):101.

7. Bashah DT, Dachew BA, Tiruneh BT. Prevalence of injury and associated factors among patients visiting the Emergency Departments of Amhara Regional State Referral Hospitals, Ethiopia: a crosssectional study. BMC emergency medicine. 2015;15(1):20.

8. Sena L, Woldemichael K. Disaster prevention and preparedness. Ethopia Public Heal Train Initiat. 2006;1:1-80.

9. Christian MD, Kollek D, Schwartz B. Emergency preparedness: what every health care worker needs to know. Canadian Journal of Emergency Medicine. 2005;7(5):330-7. 
10. Usher K, Mills J, West C, Casella E, Dorji P, Guo A, et al. Cross-sectional survey of the disaster preparedness of nurses across the A sia-P acific region. Nursing \& health sciences. 2015;17(4):43443.

11. Moabi RM. Knowledge, attitudes and practices of health care workers regarding disaster preparedness at Johannesburg hospital in Gauteng Province, South Africa: University of the Witwatersrand; 2008.

12. Nofal A, Alfayyad I, Khan A, Al Aseri Z, Abu-Shaheen A. Knowledge, attitudes, and practices of emergency department staff towards disaster and emergency preparedness at tertiary health care hospital in central Saudi Arabia. Saudi medical journal. 2018;39(11):1123.

\section{Figures}

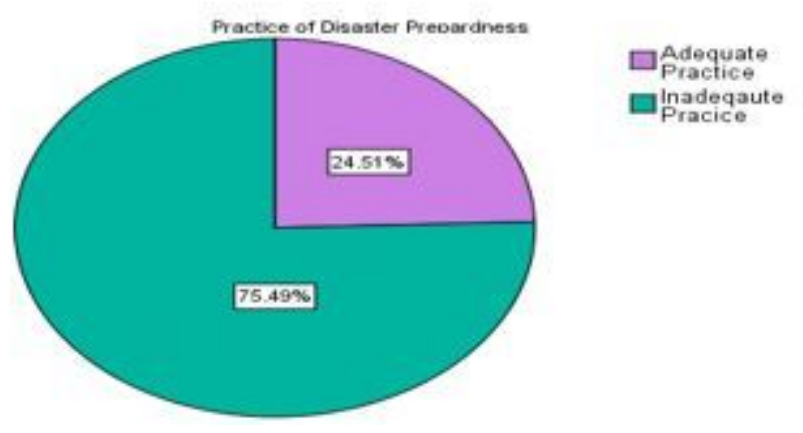

\section{Figure 1}

Practice level of participants with regard to disaster preparedness, Emergency Department, Amhara Regional State Referral Hospitals, Ethiopia, $\otimes$ Green color: Adequate disaster practice $=24.51 \% \otimes$ The other color: Inadequate disaster practice $=75.49 \%$

\section{Supplementary Files}

This is a list of supplementary files associated with this preprint. Click to download.

- AdditionalFile1.docx 